\title{
EEN BELANGRIJKE BRIEF
}

OVER

\author{
EEN BELANGRIJK ONDERWERP.
}

De levensbeschrijver van Adriaan David Cornets de Groot Jr., de heer Lauts, vermeldt een belangrijke gebeurtenis uit het leven van dien te vroeg aan de wetenschap ontvallen beoefenaar der Javaansche taal, met de volgende woorden: "Nog "geene twintig jaren bereikt hebbende, werd A. D. Cornets de "Groot Jr. tot Secretaris der residentie Soerakarta aangesteld. “Op eenen ouderdom, waarop menigeen zijne studiën naau“welijks aanvangt, had hij zijne studiën voleindigd, en zag "hij eene schitterende loopbaan voor zich geopend. Welken in"vloed op het Hof van Solo hij zich, door zijne bekendheid "met taal, zeden en gebruiken, wist te verschaffen, bleek ten "klaarste, toen de Soesoehoenan (Keizer) zich met eene Javaan"sche vrouw van ongenoegzaam hoogen rang in wettigen echt "wilde verbinden. Dit voornemen des Keizers ontdekte de "Groot op een oogenblik, toen des Residents afwezigheid hem "in de gelegenheid stelde, om naar eigen inzigt te handelen. "Dewijl de Sekretaris de persoon was, met wien de Vorst, in "zoodanig geval, moest te rade gaan, zette hij den Keizer "met ernst en met nadruk de pligten uiteen, welke op den "Soesoehoenan (zoowel in het geestelijke, als in het wereld"lijke, het hoofd zijner onderdanen) rusten, ingevolge de be"staande zeden en rangsverdeeling, beide zoo eerbiedwaardig "bij het Javaansche volk, dat het hem gelukte, den Vorst "van de ongepastheid van het voorgenomen huwelijk te over"tuigen en van hetzelve terug te brengen. De meest ondubbel"zinnige betuiging der hooge tevredenheid van het Indisch Gou"vernement mogt de veelbelovende jongeling voor deze be- 
"moeijenis inoogsten" '. Deze, in de hoofdzaak juist voorgestelde, gebeurtenis vereischt ten aanzien van de bijzonderheden nog wel eenige toelichting; het is dus een aangename taak, om de geheele toedragt van de zaak met volkomen juistheid voor te stellen. De gelegenheid daartoe is ons gegeven door de welwillendheid van de Groot's broeder, den tegenwoordigen Voorzitter van het Instituut, die den hier volgenden brief, welke de zaak in al haar bijzonderheden uiteenzet, voor de "Bijdragen" heeft willen afstaan.

$\mathrm{Na}$ deze opmerkingen zou de mededeeling van den brief zelf kunnen volgen, doch het zal misschien niet overbodig zijn een paar woorden over zijn eigenlijken inhoud te doen voorafgaan. Als een van de grootste kwalen, waarmee de Muselmansche maatschappij behebt is, moet ongetwijfeld beschouwd worden. de veelwijverij. Wel is waar is zij eigenlijk beperkt tot vierwijverij, omdat de Muselman slechts met vier vrouwen te gelijk in den echt mag verbonden zijn, maar daarnevens bestaat nog het regt om den bijslaap uit te oefenen met alle vrouwen, die hij in eigendom bezit, (zijn slavinnen), daar dit regt wordt beschouwd als opgesloten te liggen in het algemeen eigendomsregt. Behalven dat de aanwezigheid van zoo vele vrouwen bij elkander, meestal binnen een beperkte ruimte opgesloten, aanleiding geeft tot vele twisten, die dikwijls op de handelingen van den man invloed uitoefenen, geeft het groot aantal kinderen van verschillende moeders, ook aanleiding tot veel moeijelijkheden. Wanneer de man nu Vorst is, of een hoog Staatsambt bekleedt, dan kan het niet missen, of zoo veel huiselijke onaangenaamheden en geschillen hebben invloed op de regering of op algemeene belangen. Het is dus de pligt van den Indischen ambtenaar, om op deze aangelegenheden, een wakkaam oog te houden, als hij in de onmiddellijke nabijheid van inlandsche Vorsten of Grooten geplaatst is. Ook uit dit oogpunt beschouwd, verdient dus de Groot's handelwijs, ten aanzien van Pakoe Boewånå VI, vóór zijn troonsbestijging Radèn Mas Sapěrdan genaamd, allezins goedkeuring.

1 Algemeene Konst- en Letterbode, no. 5 en 6, van 1843, overgenomen in de Handelingen en Geschriften van het Indisch Genootschap, zesde jaargang, pag. 42. 


\section{SOERAKARTA, den $1^{\text {strn }}$ FebruariJ 1824 , DES MORGENS TEN 9 UREN.}

\section{Hooggeachte Heer Mac Gillavrij!}

Ik vind mij verpligt UWG. door deze extrapost kennis te geven van het op gisteren alhier voorgevallene, hetwelk ik van eenig belang beschouwende, niet twijfel, of bij UEG. dezelfde verwondering zal baren, als zulks bij mij heeft verwekt; - ten einde UEG. alle omstandigheden te doen kennen, zal ik den draad van het gebeurde volgen.

Op gisteren morgen den $31^{\text {sten }}$ Januarij kwam de eerste binnen Regent (1) Raden Ario Sosro Koesoemo bij mij in de Residentie, mij onder aflegging der groeten van Z. H. den Keizer uit H. D. naam berigtende, dat op heden (den 1sten Febr.) de volgende huwelijken met de gewone saluten zouden voltrokken worden; als:

Z. H. de Keizer met Raden adjeng Maknowijah, dochter van Pangeran Mangkoe Boemi, en met Raden adjeng Blenjik, dochter van den Prins Adi Negoro, als $2^{\text {de }}$ en $3^{\text {de }}$ vrouwen.

Prins Noto Poero met Raden adjeng Gantijah, dochter van Tjondro Diningrat.

Prins Adi Koesoemo met Raden adjeng Mangani, dochter van Prins Mangkoe Boemi.

Raden Mas Ario Mangkoe Koesoemo met Raden adjeng Sarag, dochter van Prins Adi Negoro.

En Raden Pandji Sosro Taroeno, met Raden adjeng Napsijah (2) dochter van Pangeran Mangkoe Boemi.

Betuigende mij de zendeling, dat hij in last had, hetzelfde ter kennisse te brengen van Pangeran adipati Mangkoe Negoro en den Raden adipati, met bevel aan deren laatsten, om de Regenten op dezen morgen te dien einde in de Kraton te verzamelen. Ik was al dadelijk verwonderd te vernemen, dat de Soesoehoenan zich in het huwelijk wilde begeven met de twee Raden adjengs, van welke het UEG. bekend is, dat zij in deze dagen eenen noemenwaardigen rol in den Kraton spelen, en ik begreep, dat dit een uitwerksel van haren invloed moest wezen. 
Beide deze vrouwen zijn oudere verwanten van den Vorst, dan de dochter van Pangeran Bei (3), met welke H. D. zich zoude in het huwelijk begeven, ingevolge de jongst bekomen toestemming van het Gouvernement. - Bovendien zouden zij den voorrang boven deze laatste bekomen, door vroeger in den echt te zijn verbonden, (volgens het algemeen Javaansch gebruik), ofschoon zij ook slechts den naam van Raden Ajoe en de laatste dien van Ratoe voerden. Er bestond dus voor mij geen twijfel, of des Keizers inzigt was haar, zoo al niet dadelijk, in den vervolge door den titel van Ratoe boven de dochter van Pangeran Bei te stellen, en op deze wijze, aan zijn meermalen gebleken verlangen genoegen te geven. - Aangezien Z. H. klaarblijkelijk op deze listige wijze zijnen zin zocht te erlangen, niettegenstaande UEGs. jongste ernstige aanmaningen, tegen den geest van het grootste gedeelte van het hof, en met teleurstelling van de sanctie van het Gouvernement, op zijn voorgenomen huwelijk verleend, was ik al dadelijk bedacht, om dit huwelijk tegen te gaan. Alvorens echter eenigen stap te doen, verzocht ik den Prins Boemi Noto, mij des middags in de Residentie te komen zien, met voornemen om zijn gevoelen te polsen. Tk wilde ook den Rijksbestierder bij mij roepen, om over deze zaak te spreken, - doch deze kwam mij voor, door de kennisgave, dat hij bovenge. melden last van den Vorst had bekomen, en mij daarover wilde komen onderhouden, uithoofde hij omtrent deze zaak een zwaar hoofd maakte.

Bij de komst van Boemi Noto, om 7 uren des avonds, gaf ik denzelve eerst mijne verwondering over het voornemen van den Keizer te kennen, en vraagde ronduit zijn gevoelen deswege. - De Prins betuigde mij, dat hij daarover geheel als ik dacht, en mij daarover had willen aanspreken, ware hij daarin niet verhinderd geworden door zijnen pligt jegens den Vorst, daarbij voegende, dat hij geenszins twijfelde, dat het voornemen was beide de Raden adjengs, na zijn huwelijk met de dochter van Pangeran Bei, tot Ratoe te verheffen, als wanneer zij onbetwistbaar den voorrang boven deze zouden hebben; dat het huwelijk met deze laatste was voorgenomen tijdens het leven van des Keizers vader, en alzoo voor dat Z. H. eenige hoop op den troon had, hebbende na zijn verzoek om de sanctie van het Gouvernement kennis met deze Raden adjengs gemaakt, zoodat het toen te laat was, om dezen en niet eerst- 
genoemde te trouwen, en dat hij nu op deze wijze zijnen zin zocht te bevredigen, waardoor hij Prins volkomen overtuigd was, dat het Gouvernement zoude gecompromitteerd wezen, en dewelke het ongenoegen van velen zoude verwekken, zoowel als zulks hem niet aangenaam was, betuigende voorts, dat het eens zoo zijnde, men slechts voor de gevolgen behoedzaam moest wezen.

Op dit laatste antwoordde ik hem onmiddellijk, dat ik voornemens was de huwelijken provisioneel te stuiten, en ik hierin door het gevoelen van hem Prins wierd gesterkt, hetwelk ik had willen inwinnen, alvorens dien stap te doen.

In hartelijke en aandoenelijke bewoordingen viel den Prins daarop in, dat hij geen anderen wensch had gevoed, doch mij een dusdanig voorstel niet had durven of mogen doen, verklarende dit volkomen met de eer van het Gouvernement, het welvaren van den Kraton, en den geest van het hof overeen te komen.

De Rijksbestierder daarop ingekomen zijnde, sprak ik hem op dezelfde wijze afzonderlijk over de zaak. Zonder bekend te zijn met mijn voornemen, noch met hetgeen Boemi Noto mij had verklaard, hetuigde hij, in denzelfden geest als de Prins, zich niet met des Keizers voornemen te kunnen vereenigen, en deswege over den Vorst zeer ontevreden te zijn. - Hij verhaalde mij, dat voor c. c. een kwartier uurs de Keizer bij hem was geweest, daar Z. H. hem dien dag twee malen had laten roepen, en hij uithoofde van ongesteldheid niet had kunnen komen; dat Z. H. hem als gewoonlijk vader noemende, hij hem zoude hebben toegevoegd: "Uwe Hoogheid gelieft mij nit vo"rige betrekkingen vader te noemen, doch ik heb reden te "twijfelen, of dit van harte gemeend is," - op des vorsten vraag waarom, zoude hij geantwoord hebben, "men dient den raad van eenen vader te volgen;” en de Keizer zweeg! Daarop kwam bij den Rijksbestierder een oppasser, dien ik had gezonden, om zijne komst in de Residentie te verhaasten, waarop de Keizer, zulks ziende, dadelijk was teruggekeerd.

Ik zoude dit verhaal als overdreven beschouwd hebben, had de Rijksbestierder dit naderhand niet in mijne tegenwoordigheid aan Boemi Noto herhaald.

Hij verklaarde al verder dat de saluten, ofschoon men had doen voorkomen als of zij ter eere der andere huwelijken wa- 
ren, meerendeels zouden dienen ter viering van 's Vorsten verbindtenis.

Overtuigd ook den Rijksbestierder op mijne hand te hebben, maakte ik hem mijn voornemen bekend; hij spaarde geene uitdrukkingen van goedkeuring.

Ik gaf daarop den Rijksbestierder en Boemi Noto gezamenlijk te kennen, dat ik dadelijk naar den Kraton wilde gaan, en verzocht hen mij te vergezellen, waartegen eerstgenoemde inbragt, dat hij den Vorst dien dag twee malen had geweigerd in den Kraton te komen uithoofde van ongesteldheid; op mijn aandringen stemde hij toe, en ik beloofde den Vorst te verzekeren, dat het mijn verlangen was geweest, dat beiden binnenkwamen.

$\mathrm{Na}$ als gewoonlijk audiëntie verzocht te hebben, ging ik, met Boemi Noto en den Rijksbestierder, gisteren avond om half negen uren naar den Kraton, alwaar alle 's Vorsten vrouwelijke verwanten verzameld waren, zooals het gebruik is, eenige dagen voor het huwelijk (4); allen waren in de Probo joso (5), welks deuren ik gesloten vond, staande voor dezelve verscheiden gamelan's en het geheele plein was met volk gevuld (zijnde echter alles in eene plegtige stilte) — zoodat reeds alle voorafgaande vermaken een aanvang hadden genomen.

De Keizer zat als gebruikelijk in de pendopo, in gezelschap van de Prinsen Poerbojo en Bei, allen in gewone staatsie gekleed.

Onhoorbaar voor de omstanders, gaf ik den Vorst het volgende in vriendelijke, doch krachtige bewoordingen te kennen.

Dat ik dien morgen de boodschap van Zijne Hoogheid had ontvangen, en ik niet kon nalaten mijne verwondering te betuigen over H. D. voornemen om den volgenden dag met voornoemden Raden adjengs te trouwen.

Dat, ofschoon Z. Hs. intentie was, deze Raden adjeng's slechts den naam van Raden Ajoe toe te kennen, ik beducht was, dat in den vervolge onaangenaamheden konden ontstaan, zoo uithoofde dat beide oudere verwanten dan de dochter van Pangeran Bei waren, als omdat zij boven deze reeds den voorrang zouden hebben door een vroeger huwelijk.

Dat het Gouvernement Z. H. op deszelfs verzoek plegtiglijk had toegestaan, zich met de dochter van Pangeran Bei in den echt te begeven en deze tot Keizerin te verheffen; dat hetzelve alzoo gecompromitteerd zoude wezen door, zoo niet al 
dadelijk, in den vervolge door 's Vorsten voorgenomen maatregel, welke zonder voorkennis van Z. E. den GouverneurGeneraal zoude plaats hebben, anderen boven haar verheven te zien.

Dat ik ook voor de rust van het hof en 's Keizers belangen dezen stap als ondoelmatig beschouwde, zoowel voor het tegenwoordige als voor de waarschijnlijke gevolgen van dien (doelende op de te voorziene verheffing tot Ratoe van beide prinsessen), en dat ik veronderstelde dat Z. H. in deze met mijn gevoelen zoude overeenstemmen.

- Dat ik alvorens in deze iets te verrigten, deswege den Prins Boemi Noto en den Rijksbestierder had onderhouden, die met mij volkomen overeenkwamen.

Dat ik mij dierhalve verpligt rekende Zijne Hoogheid te verzoeken, deze huwelijken voor als nog te staken, en ten minsten geen gevolg te doen nemen binnen de vijf dagen na de voltrekking van zijnen echt met de dochter van Pangeran Bei, indien daartegen geene objecties zouden bestaan, tot welk einde ik mij bij het Gouvernement zoude adresseren.

De Keizer betuigde mij aan mijnen raad te zullen gehoor geven, en het nut daarvan geheel te gevoelen. Ik vermeende echter te bemerken, dat dit Z. H. niet zeer aangenaam was, gelijk ligtelijk te begrijpen is.

De Prins Boemi Noto hield daarop een lang gesprek met den Vorst, hetwelk eenlijk voor mij hoorbaar was, waarin hij Zijne Hoogheid betoogde hoe doelmatig en noodzakelijk mijn eisch was, dat hij met den Rijksbestierder daarmede volkomen overeenstemde, en dat de Vorst zich op mijnen en hunnen raad konde verlaten, waarop de Vorst in gewenschte bewoordingen antwoordde.

Op voorstel van Boemi Noto, stemde de Keizer toe, dat die Prins het beslotene aan de daar tegenwoordige Pangerans Poerbojo en Bei mededeelde, nemende dezen daarin genoegen!

Ik verzocht daarna Zijne Hoogheid, den Rijksbestierder de zaak te willen kennelijk maken, en de noodige contra-orders te geven, tot welk einde hij wierd voorgeroepen, en hem in dien zin bevelen werden gegeven.

Laatstelijk betuigde ik Zijne Hoogheid, dat ik genoegen nam in de overige bekend gemaakte huwelijken, welke ook op dezen morgen worden voltrokken. - Ik heb bevonden, dat deze enkel zijn geschikt, om de oudere verwanten van de twee 
Raden adjengs, die de Keizer wilde huwen, uit te trouwen, gelijk de Javađnsche gewoonte medebrengt, dat moet geschied zijn, alvorens een jongere zich in den echt mag begeven.

De Keizer stelde daarna een toast in, om mij voor den goeden raad te bedanken, zoowel als voor het belang, dat ik in zijn bestaan en de rust van het hof toonde te stellen!

Hierna nam ik afscheid, in de overtuiging van wel te hebben gehandeld, het grootste gedeelte van het hof voor misnoegen te hebben behoed, de eer van ons Gouvernement te hebben opgehouden, en het Javaasch publiek vertrouwen ten mijnen opzigte ingeboezemd te hebben.

Ik verzoek $U_{E G}{ }^{\text {. }}$. dringend mijne handelingen in deze te willen approberen, twijfelende ik geenzins, of UEG. zal daartoe termes vinden, - Natuurlijkerwijze aan UEG. overlatende, om deze zaak des noodig achtende voor het Gouvernement te brengen, en te bewerken, dat ik zoodra mogelijk met bevelen worde voorzien, neem ik de vrijheid UEG. in consideratie te geven, dat, volgens mijn gebrekkig oordeel, het huwelijk van den Keizer met de meergenoemde twee Raden adjengs, na dat met de dochter van Pangeran Bei, zoude kunnen worden ingewilligd, om ook den Keizer eenigzins genoegen te geven (6), echter onder zoodanige wijzigingen, als ons kunnen verzekeren, dat zij nimmer den voorrang zullen hebben boven de dochter van Pangeran Bei, en zulks ter handhaving van hetgeen eens door het Gouvernement is bekrachtigd, en ter voorkoming van misnoegen bij eenige der voornaamste hofgrooten.

UEG. gelieve mij met een spoedig antwoord te vereeren, en de verzekering aan te nemen van de hoogachting, waarmede ik de eer heb mij te noemen,

UWEG*. Geh. Dr.

NB. De Prins Mangkoe Negoro (7) is zoo even bij mij gekomen en is zeer vergenoegd over mijne handelwijze. 


\section{AANTEEKENINGEN.}

(1) Degeen, die hier binnen-Regent genoemd wordt, is ongetwijfeld een ambtenaar met den rang van Toeměnggoeng, die dienst deed binnen den Kraton.

(2) Opmerking verdienen sommige van de genoemde namen der Prinsessen, zoo als Maknåwijah, Mangani, Napsijah, Saraq. De drie eerste namen zijn zeer zeker ontleend aan de scholastieke theologie van den Islam, waar zij worden gebruikt om verschillende soorten van Allah's attributen (çipaat) te beteekenen: men zie daarover El-Senusi's Begriffsentwickelung des Muhammedanischen Glaubensbekentnisses, Arabisch und Deutsch met Anmerkungen von $\mathrm{Dr}$. M. Wolff, een boekje, waarvan de Arabische tekst onder zijn naam Omm 'l-Barahien, blijkens de mededeeling van Raffles, op Java onder de inlanders bekend is. De vierde naam Saraq is de gewone, aan het Arabisch ontleende, benaming van de Muselmansche wet, die al de verplig. tingen voor het geheele leven beschrijft. In den Javaanschen brief, die in de zesde aanteekening wordt aangehaald, komt ook de naam van een Prins Saréngat voor, welke naam, in het Arabisch Sjariat luidende, hetzelfde beteekent als Saraq; ja, zelfs vindt men een Prinsennaam aan het hof van Soerakarta, luidende Sapingi, dat niets anders zijn kan dan de al gemeen bekende naam van Sjafi'i, den stichter der wetgeleerde secte, waarvan de volgelingen in den Archipel de overhand hebben.

(3) Pangeran Bei, beter Pangéran Ngabèi is de gewone titel van den oudsten der onechte zonen van den Vorst. Onder onechte zonen verstaat men de buiten echt verwekte, d. i. de zonen, die geboren zijn uit de vrouwen, waarmee de Vorst niet in het huwelijk was vereenigd, maar die als zoogenoemde bijwijven zijn genomen. 
Tot regt verstand van de houding, die Boemi Nåtå en de Rijksbestierder in deze zaak aannemen, kan een Javaansche brief $\left(\mathrm{n}^{0} .40\right)$ uit de Javaansche Brieven, Berigten, Verslagen enz. dienen. De bedoelde brief is van dezen Pangéran Arijå Boemi Nåtå zelf aan Pangéran Arijå Mangkoe Boemi te Ambon, waarin hij hem onder anderen mededeelt de verheffing van den zestienjarigen Radèn Mas Sapardan tot Soesoehoenan, en de benoeming van hem zelf en van den Rijksbestierder tot raadgevers (kapópóhan pratikěl), benevens hun verzoek om toevoeging van den Pangéran Arijå Poeråbåjå en van Pangéran Ngabèi.

(4) Het hier bedoelde gebruik heet Midådarèni, een woord, waarmee beteekend wordt het gezelschap met de daarbij gebruikelijke plegtigheden, dat den avond vóór het voltrekken van een huwelijk wordt gehouden. Dat gebruik is waarschijnlijk een overblijfsel van den Hindoe-tijd, want het aangehaalde Javaansche woord stamt af van een Sanskritsch woord, dat luchtgeest beteekent en nu nog in het Javaansch gebruikt wordt voor hemelnimf, engelin (widådari).

(5) Pråbå-jåså, of Pråbå-jěkså, is een woning binnen den Kraton, die men het Serail zou kunnen noemen.

(6) In de Javaansche Brieven, Berigten, Verslagen enz. vind $i k$ onder $n^{0}$. 45 een brief van dezen Soesoehoenan Pakoe Boewånå VI aan den Pangéran Arijå Mangkoe Boemi, waaruit blijkt dat de schrijver van den brief reeds in dezelfde maand Februarij de twee genoemde Prinsessen getrouwd heeft, en dat hij bij die gelegenheid aan de Radèn Adjěng Maknåwijah den titel heeft gegeven van Radèn Ajoe Sěpoeh en aan de Radèn Adjĕng Balěnjik dien van Radèn Ajoe Anèm. Uit dien brief blijkt evenwel ook, dat de Soesoehoenan den $15^{\text {den }}$ Februarij 1824 getrouwd is met de dochter van den Pangéran Ngabèì, die heette Radèn Adjěng Koesijah, bij deze gelegenheid tot Ratoe Mas benoemd, en dat de huwelijken met de beide, zoo even genoemde, prinsessen eerst vijf dagen later voltrokken werden.

(7) De Pangéran Arijå Mangkoe Neggårå is een zoogenoemde onafhankelijke Prins, wiens landen binnen het gebied van den Soesoehoenan liggen. Zijn onafhankelijkheid, namelijk van den Soesoehoenan, is echter niet onbeperkt, want, behalve in regeringsaangelegenheden, zooals de regtsbedeeling, staat hij ook in naauwe betrekking tot de familieaangelegenheden

VI. (X.) 
van den Vorst, zoo dat hij bij alle plegtige ceremoniën en festiviteiten tegenwoordig zijn moet.

Ten slotte dient met een woord te worden gewezen op het cordaat gedrag van den jeugdigen de Groot, die in het jaar 1824, toen het er aan het Hof te Soerakarta geheel anders uitzag dan tegenwoordig, op eigen verantwoordelijkheid dusdanig durfde handelen.

S. K. 